\title{
The Prediction Model of Birth Weight Based on the Weight of Expectant Mothers at the Health Centers in Padang 2016
}

\section{Zikra Hanim, Defriman Djafri, and Masrizal Dt. Mangguang}

Faculty of Public Health, Andalas University, Padang, Indonesia

\section{Abstract}

A low prepregnancy weight and pregnancy weight gain cause low birth weight. The purpose of this study was to describe the correlation between the pre-pregnancy weight every trimester weight gain and body mass index pre-pregnancy with the birth weight and to determine the most influential factors that have a relation with the birth weight. This study used a retrospective cohort design with the number of samples is 153 expectant mothers, including the babies that took an antenatal care and the women who gave births health centers in Padang 2016. The data were collected through cohort

Corresponding Author:

Zikra Hanim

zikrahanim@gmail.com

Received: 26 December 2018 Accepted: 23 February 2019 Published: 7 March 2019

Publishing services provided by Knowledge E

(c) Zikra Hanim et al. This article is distributed under the terms of the Creative Commons

Attribution License, which permits unrestricted use and redistribution provided that the original author and source are credited.

Selection and Peer-review under the responsibility of the $2 \mathrm{nd}$ International Meeting of Public Health 2016 Conference Committee.

\section{G OPEN ACCESS} register and birth date. Correlation analysis and multiple linear regression were used to determine the strength and direction of relationship independent variables and birth weight. Based on this study result, it was found that the average of birth weight is 3.135.23 grams (95\% Cl: $3.078 .32-3.192 .13)$. The maternal weight gained of expectant mother in the first trimester $(p=0.029)$ and second trimester $(p=0.005)$ had a significant correlation with the birth weight, while the pre pregnancy weight $(p=0.051)$, maternal weight gained in the third trimester $(p=0.893)$, and the pre pregnancy BMI $(p=0.107)$ had no significant correlation with the birth weight. Based on prediction model, it is acquired that the birth weight $=2.605 .38+7.35$ prepregnancy weight +0.035 second trimester weight gain. The most influential variable was the maternal weight gain in the second trimester.

Keywords: Pregnancy weight; birth weight; BMI

\section{Introduction}

The nutritional status of the mother strongly influences the nutritional status of the newborn before pregnancy, the pregnancy and until birth. Pregnancy is a physiological process, the most critical phase of the start of a child's growth in the future. Adequate nutrition is needed for the mother and the fetus to increase nutritional needs during pregnancy (IDH Survey 2012). One way to assess the nutritional status of mothers during pregnancy is through anthropometric examination. Maternal nutritional status during 
pregnancy is influenced by several factors, such as pre-pregnancy weight, height, body mass index, and upper arm circumference (MUAC).

Furthermore, it is following the mother's weight gain during pregnancy. Based on WHO recommendations, pregnancy weight gain with a good nutritional status is 10-14 $\mathrm{kg}$. Factors that support the intervention in monitoring the health of pregnant women who marked mother weight gain will affect birth weight (Arisman 2004).

The adverse effects may occur if weight gain during pregnancy lacks among others birthweight infants less or not normal (less than 2.500 grams), congenital disabilities, neonatal death, LBW would be very risky to the baby such as infection, morbidity, and mortality (Achadi et al. 1997).

Maternal weight gain during pregnancy directly affects birth weight and is influenced by various factors, including nutritional status of pre-pregnant and sociodemographic factors - a low pre-pregnancy weight correlated with low weight gain during pregnancy. Low weight gain in first and second trimester has a more significant impact on birth weight. If the third-trimester weight gain remains low, then pregnant women will have a higher risk to the incidence of Intrauterine Growth Restriction (IUGR) (Sari et al. 2013).

Based on the profile of West Sumatra Health Office, the prevalence of birth weight babies in West Sumatra quite fluctuated. Judging from 2012, there were 1.9\% babies with low birth weight, and $98.1 \%$ with normal birth weight while in 2013 , there were $2.2 \%$ with low birth weight and $97.8 \%$ with normal birth weight. In 2014, it's 1.68\% with low birth weight 98.3\% with normal birth weight while in 2015 there were 58.529 live births and $2.35 \%$ with low birth weight, $97.6 \%$ with normal birth weight. In Padang, the prevalence of LBW increased from 2014 to 2015 . The prevalence of babies with low birth weight increase from $1.74 \%$ in 2014 to $2.2 \%$ in 2015.

The nutritional status of pregnant women is most sensitive to predict the outcome of pregnancy which is a pre-pregnant weight and maternal weight gain during pregnancy. This method can determine the quality of long-term consequences of fertility and life of the mother and baby. Maternal weight gain that is an inadequate mother will produce an optimal outcome in the sense of preventing complications (pregnancy and post-delivery) and optimal infant outcome, namely the occurrence of fetal growth and maturation optimal prevention of morbidity and mortality during pregnancy and perinatal period. Knowledgeable weight during pregnancy by trimester will be used to determine when intervention in pregnant women needs to be done (Irawati et al. 2013).

Based on the explanation above, the writer interested in studying "The Prediction Model Birth Weight based on the Weight of expectant mother with variable prepregnancy weight, weight gain each trimester and pre-pregnant BMI at The Health Centers in Padang 2016". 


\section{Methods}

This study used a retrospective cohortt with 153 expectant mothers as samples, including the babies that took an antenatal care and the women who gave births Health Centers in Padang from January 2015 - March 2016. Sampling was done by total sampling technique - the data were collected through cohort register and birth data. Correlation analysis and multiple linear regression were used to determine the strength and direction of relationship independent variables and birth weight.

\section{Results}

Table 1 showed the average of birth weight was 3.135 .23 grams, maternal weight gain in first trimester was 899.22 grams, maternal weight gain in second trimester 3.843.14 grams, maternal weight gain in third trimester was 3.732 .03 grams, pre-pregnancy weight 53.591 kilograms and the average of pre-pregnant BMI was 22.9213 .

TABLE 1: The Frequency Distribution of Independent and Dependent Variables.

Variables
Pre Pregnancy
Weight (kg)
1sttrimester weight
gain
2nd-trimester
weight gain
3rd-trimester weight
gain
Pre Pregnancy BMl
Birth Weight

\begin{tabular}{|c|c|c|c|c|c|c|}
\hline Mean & Median & Mode & SD & Min & Maks & $95 \%$ Cl \\
\hline 53.591 & 53.48 & 49.4 & 1.0593 & 33.80 & 84.68 & $51.899-55.283$ \\
\hline 899.22 & 760.00 & 0 & 776.742 & -1330 & 5.670 & $775.15-1.023 .28$ \\
\hline 3.843 .14 & 3.000 .00 & 3.000 & 2.758 & 0 & 18.000 & $3.402 .61-4.283 .67$ \\
\hline 3.732 .03 & 4.000 .00 & 3.000 & 3.595 & -9000 & 20.000 & $3.157 .88-4.306 .17$ \\
\hline 22.9213 & 22.86 & 19.36 & 4.28646 & 13.88 & 34.96 & $22.2367-23.606$ \\
\hline 3.135 .23 & 3.100 & 3.000 & 356.271 & 2.000 & 4.500 & $3.078 .32-3192.13$ \\
\hline
\end{tabular}

Table 2 showed that there was a significant association of first-trimester weight gain $(p=0.029)$ and second-trimester weight gain (0.005) with birth weight. In addition, there was no significant association among weight pre-pregnancy weight $(p=0.051)$, third trimester weight gain $(p=0.893)$ and pre-pregnancy BMI $(p=0.107)$ with a birth weight.

TABLE 2: Correlation and Regression Analysis Independent Variables with Birth Weight.

Variables
Pre Pregnancy Weight
1st trimester weight gain
2nd trimester weight gain
3rd trimester weight gain
Pre pregnancy BMl

\begin{tabular}{|c|c|}
\hline $\mathbf{R}$ & $\mathbf{R}^{2}$ \\
\hline 0.158 & 0.025 \\
\hline 0.176 & 0.031 \\
\hline 0.226 & 0.051 \\
\hline 0.011 & 0.000 \\
\hline 0.131 & 0.017 \\
\hline
\end{tabular}

\begin{tabular}{c} 
Equation \\
\hline Bbaby $=2850.759+5.308 *$ Bbpra \\
\hline Bbaby $=3062.455+0.081^{*}$ Tri1 \\
Bbaby $=3023.147+0.029 *$ Tri 2 \\
Bbaby $=3139.268-0.001^{*}$ Tri3 \\
Bbaby $=2885.903+10.877^{*}$ IMTpra
\end{tabular}

\begin{tabular}{|c|}
\hline p value \\
0.051 \\
0.029 \\
\hline 0.005 \\
0.893 \\
0.107 \\
\hline
\end{tabular}


Table 3 showed the birthweight estimation model in Health Centers Padang were if pre-pregnancy weight increase by $1 \mathrm{~kg}$, birth weight babies would rise 7.348 grams after the controlled variable maternal weight gain in the second trimester and if second trimester weight gain increase 1000 grams, the birth weight would increase 35 grams after the controlled variable pre-pregnancy weight.

TABLE 3: Final Multivariate Model.

Variable
(Constant)
Pre Pregnancy weight
2nd trimester weight gain

2nd trimester weight gain

\begin{tabular}{|c|c|}
\hline \multicolumn{2}{|c|}{ Coef Non Standart } \\
\hline B & SE \\
\hline 2.605 .380 & 159.391 \\
\hline 7.348 & 2.677 \\
\hline .035 & .010 \\
\hline
\end{tabular}

.010


\section{Discussion}

Pre-pregnant mother's weight is to determine the prognosis and the decision whether or not to do nutrition therapy. Poor nutritional status is characterized by weight before pregnancy $10 \%$ below or above the ideal weight (Arisman 2004). Pre-pregnancy weight and weight gain during pregnancy are clinical parameters. That is important for predicting low pre-pregnancy weight or a low weight gain during pregnancy tend to low birth weight babies (Amirudin 2014).

In the first trimester of the mother, they need of adequate nutritional intake and energy balance to meet the range of weight gain which should be $1-2 \mathrm{~kg}$ (350-400 g / week) (Soetjiningsih1995). Women who are suffering from malnutrition before pregnancy or during the first week of pregnancy tend to give birth to babies who suffered brain damage and a sum - bone marrow because the central nervous system is susceptible in the 2-5 first weeks (Arisman 2010).

Maternal weight gain is not the same, but in general, the highest weight gain is at the gestational age 16-20 weeks (second trimester), and low weight gain in the first ten weeks of pregnancy. Fetal malnutrition in the second trimester may cause interference photo placenta relationship, infants born with less weight and lean body proportions (Amirudin 2014).

Mothers suffering from malnutrition during the last week of pregnancy give birth to babies with low birth weight $(<2500 \mathrm{~g})$ because of fatty tissue during tri-semester III (Arisman 2010). Low weight gain in the third trimester causes brain growth run at the expense of the growth of the body, a baby born with an average weight, with a small body proportion, and in the years of life, it will be reduced weight (Sari et al. 2013). 
Body mass index (BMI) pre-expectant mother is the most influential factor in maternal weight gain during pregnancy. Low pre-pregnant BMI IS still considered a sign of nutritional supplies minimal tissue, which increases the risk of pregnancy outcomes in women. Mothers who start pregnancy with a low BMI should consume energy and nutrients are adequate to gain adequate weight gain during pregnancy (Sari et al. 2013) preexpectant mothers $\mathrm{BMI}$ is a risk factor most effect on weight gain for pregnant women (Irawati et al. 2013).

Predictive models for birth weight can obtained by using the variable maternal weight before pregnancy and weight gain in second trimester. The meaning coefficient for each variable is if pre-pregnancy weight increase by $1 \mathrm{~kg}$, birth weight babies will rise 7.348 grams and if second-trimester weight gain increases 1000 grams, the birth weight will increase 35 grams. The result of this analysis shows that the most influencing variable in the baby's birth weight is maternal weight gain in the second trimester.

\section{Conclusion}

Model prediction of birth weight was $2.605 .383+7.348+0.035$, pre-pregnancy accretion of the second trimester 2 . The most dominant variable associated with infant birth weight was mother's weight gain in second trimester.

\section{References}

[1] Achadi EL, Nurhayati P, Setyawan. 1997. "Effect of Maternal Hb third trimester of Genesis LBW, premature, and IUGR, in the district and sub-district Sliyeg Gabus Wetan, Indramayu regency, West Java." Journal of Epidemiology Indonesia. Volume I Issue 3.

[2] Amiruddin R. 2014.Determinants of Maternal and Child Health. Jakarta: Trans Info Media.

[3] Arisman. 2004.Nutrition in the Life Cycle. Jakarta: Book Medical Publishers EGC.

[4] _ 2010.Nutrition in the Life Cycle. Jakarta: EGC.

[5] Irawati A, R. 2013. "Tachmalina body mass index Pre Pregnant Mothers as a risk factor for weight gain in pregnant women and Ciwaringin Kebon Kelapa, Central Bogor subdistrict, Bogor City." Journal of Ecology of Health. Vol 12: 117-27.

[6] Ministry of Health. 2013. Indonesia Demographic Health Survey 2012. Jakarta.

[7] Sari M, Sudiarti T. 2013.“Infant Birth Weight Prediction Model Based Pregnancy Weight."Public Health: the National Public Health Journal. 7: 8.

[8] Soetjiningsih. 1995. Growth. Jakarta: EGC. 
[9] The West Sumatra Provincial Health Office. 2014. Health Profile of West Sumatra Padang Year 2014. West Sumatra Provincial Health Office. 